\title{
Effect of Seedling Age and Water Management on the Performance of Boro Rice (Oryza sativa L.) Variety BRRI Dhan28
}

\author{
M. S. Ali, M. A. Hasan, S. Sikder, M. R. Islam* and M. H. R. Hafiz \\ Department of Crop Physiology and Ecology, Hajee Mohammad Danesh Science and Technology \\ University,Dinajpur-5200, Bangladesh
}

*Corresponding author and Email: rabiul_hstu@yahoo.com

Received: 17 July 2013 Accepted: 06 December 2013

\begin{abstract}
A field experiment was conducted at the research farm of Crop Physiology and Ecology Department, Hajee Mohammad Danesh Science and Technology University, Dinajpur, Bangladesh during November 2010 to May 2011 to find out the effect of seedlings age and water management on tillering behavior, growth dynamics, yield and yield contributing characters of BRRI dhan28. The experiment was laid out in two factors randomized complete block design with four replications taking two seedlings age i.e. 15 and 30-d-old seedlings at transplanting and two water management practices viz. continuous flooding and intermittent irrigation. Fifteen-d-old seedlings provided greater ability of tiller production, dry matter accumulation and more leaf area than those of 30-d-old seedlings but the ability was influenced more with intermittent irrigation than continuous flooding. Transplanting of younger seedlings provided more effective tillers hill ${ }^{-1}$, filled grains panicle ${ }^{-1}$, thousand grain weight and finally grain yield than those of the older one but the younger seedlings interacted with intermittent irrigation significantly to explore all of these parameters. Fifteen-d-old seedlings of took shorter time to be matured than 30-d-old seedlings in both continuous flooded and intermittent irrigated condition. Again the crop matured 2 days earlier in intermittent irrigated plots than continuous flooded plots for both 15 and 30-d-old seedlings. Finally it may be concluded that transplanting of younger seedlings in combination with intermittent irrigation performed the best in tiller production, growth dynamics, yield and yield contributing characters.
\end{abstract}

Keywords: Seedlings age, intermittent irrigation, growth, yield, rice

\section{Introduction}

Rice (Oryza sativa L.) is the $1^{\text {st }}$ ranking cereal crop in terms of area and production in Bangladesh though the average yield of $2.82 \mathrm{t} \mathrm{ha}^{-}$ ${ }^{1}$ is very low as compared to that of Egypt (8.4 t $\left.\mathrm{ha}^{-1}\right)$ and USA (6.6 $\left.\mathrm{t} \mathrm{ha}^{-1}\right)$ (BBS, 2010). There are many reasons for this low yield. The important one is use of unsuitable aged seedlings and different water levels by farmers. The combined effect of these factors usually produces high seedlings mortality just after transplanting. Seedlings age at transplanting is an important factor for uniform stand of rice and regulating its growth and yield (Bassi et al., 1994). Tiller dynamics of the rice plant greatly depends on the age of seedlings at transplanting (Pasuquin et al., 2008). Tillering and growth of rice proceed normally when optimum aged seedlings are transplanted at the right time (Mobasser et al., 2007). The farmers of Bangladesh are habituated to irrigate rice as 
much as possible and maintain high submergence throughout the crop period with the wrong notion that yields could be increased with increased water input. The continuous land submergence leads to considerable loss of water through deep percolation and other means (Bouman, 2001). On the other hand, submerging rice field brings a series of physical, chemical and microbial changes in the soil, which profoundly affects growth of rice plant as well as availability, loss and absorption of nutrients (Ghildyal, 1978). Inefficient water use not only increases cost of irrigation, but declines the water table, increases arsenic contamination and may emit the green house gases from submerged rice field that lead to climate change in the world (Wang et al., 1998). Therefore, considering the above points the present study was conducted to determine the effect of seedlings age and water management on tillering behavior, growth dynamics, yield and yield contributing characters of BRRI dhan28.

\section{Materials and Methods}

The experiment was set up at the research farm of Crop Physiology and Ecology Department, Hajee Mohammad Danesh Science and Technology University, Dinajpur, Bangladesh at $25^{\circ} 39^{\prime} \mathrm{N}$ latitude and $88^{\circ} 41^{\prime} \mathrm{E}$ longitudes during November 2010 to May 2011. The experiment was laid out in a two factors factorial randomized complete block design i.e. Factor A: Seedlings age: 15 and 30-d-old seedlings and Factor B: Water management: Continuous flooding ( 3 to $5 \mathrm{~cm}$ water was kept throughout the growing period by checking water level every 24- hour) and intermittent irrigation (intermittent irrigation treatment consisted of providing light irrigations to keep the soil moist. After panicle initiation, a thin layer (1 to $2 \mathrm{~cm}$ ) of water was maintained in this treatment and the field was completely drained 10 to 15 days before harvest). Water treatments were started one week after transplanting when the transplanting shock had abated. The total number of plots was 16 and the unit plots size was $12 \mathrm{~m}^{2}$ $(4 \mathrm{~m} \times 3 \mathrm{~m})$ having a plots to plots and block to block distance of 1.0 and $2.0 \mathrm{~m}$, respectively. Fertilizer was applied at the rate of 140-35-10025-3.5 kg ha ${ }^{-1} \mathrm{~N}, \mathrm{P}, \mathrm{K}, \mathrm{S}$, and $\mathrm{Zn}$ in the form of urea, triple supper phosphate, muriate of potash, gypsum and zinc sulphate, respectively (BARC, 2005). The 15 and 30-d-old seedlings of rice (Variety- BRRI dhan28) were transplanted on 12.12.2010 as per treatment design having $20 \mathrm{~cm}$ $\times 20 \mathrm{~cm}$ spacing. Three healthy seedlings were transplanted per hill. Intercultural operations were done as per requirement. At 45 days after transplanting (DAT) and at anthesis, three hills were selected randomly from two peripheral line rather than boarder line to collect data on tillers hill $^{-1}$, leaf area index (LAI) and dry matter hill ${ }^{-1}$. Leaf area was measured using leaf area meter (Model: CI 202, USA) and dry matter hill ${ }^{-1}$ was obtained by drying the collected hills in an electric oven (Model- E28\# 03-54639, Binder, Germany) at $70^{\circ} \mathrm{C}$ for 72 hours and weighing them in an electrical balance (Model- AND EK300 i). Plant height, number of tillers hill' ${ }^{-1}$ at 45 DAT, number of tillers, effective tillers and panicles hill $^{-1}$ during harvesting, panicle length and number of filled and unfilled grains of panicle $^{-1}$, grain yield and straw yield were recorded properly. The data were analyzed by partitioning the total variance by using MSTAT program. The treatment means were compared using Duncan's Multiple Range Test (DMRT at $5 \%$ level of significance (Gomez and Gomez, 1984).

\section{Results and Discussion}

\subsection{Number of tillers hill $^{-1}$}

Tillering behavior was found to be significantly influenced by the interaction effect of seedlings age and water management (Table 1). At 45 DAT, the highest number of tillers hill ${ }^{-1}$ (31.5) was obtained when 15-d-old seedlings were transplanted in intermittent irrigated plots which was followed by that (25.2) when the seedlings of the same age was transplanted in continuous flooded plots and 30-d-old seedlings produced the lowest number of tillers hill ${ }^{-1}$ (18.0) when they were transplanted in continuous flooded plots which was followed by that (21.3) obtained 
from the seedlings of the same age transplanted in intermittent irrigated plots. At anthesis (70 DAT), 15-d-old seedlings transplanted in intermittent irrigated plots produced the highest number of tillers hill ${ }^{-1}$ (32.2) which was followed by the seedlings of same age that was transplanted in continuous flooded plots and 30d-old seedlings produced the lowest number of tillers hill ${ }^{-1}$ (21.2) when they were transplanted in continuous flooded plots which was followed by the seedlings of same age transplanted in intermittent irrigated plots (22.9). But 30-d-old seedlings did not differ significantly in both the water management practices. The results indicate that younger seedlings produced higher number of tillers hill ${ }^{-1}$ than the older seedlings in both the water management treatments. Ginigaddara and Ranamukhaarachchi (2011) also found that younger seedlings had greater ability to produce greater number of tillers hill $^{-1}$ than older seedlings. Singh et al. (2007) observed that when a seedling is transplanted carefully at the initial growth stage, the trauma of root damage caused during uprooting is minimized following a rapid growth with short phyllochrons. Krishna et al. (2008) noted that rice seedlings transplanted before commencing the fourth phyllochron retained their higher tillering potential than that of seedlings of more than 14 days old. Makarim et al. (2002) stated that 14 days old seedlings have performed better in tiller production than transplanting 21 to 23 -d-old seedlings. The results also indicate that intermittent irrigation provided greater number of tillers hill $^{-1}$ than continuous flooding but younger seedlings performed better in both the irrigation regimes than the older seedlings.

\subsection{Leaf area index}

Age of seedlings at transplanting and water management interacted significantly to influence the LAI both at 45 days after transplanting and at anthesis (Table 1). At 45 DAT, the highest leaf area index was recorded from 15-d-old seedlings transplanted in intermittent irrigated plots (3.51) which was followed by that (2.88) recorded from the seedlings of same age transplanted in continuous flooded plots. Thirty-d-old seedlings transplanted in continuous flooded plots provided the lowest LAI (2.01) which was followed by that (2.27) recorded from the seedlings of the same age transplanted in intermittent irrigated plots. At anthesis, 15-d-old seedlings transplanted in intermittent irrigated plots provided the highest LAI (3.79) which was followed by that (3.03) recorded from the seedlings of same age transplanted in continuous flooded plots. Thirty-d-old seedlings transplanted in continuous flooded plots provided the lowest LAI (2.35) which was followed by that (2.57) recorded from the seedlings of same age transplanted in intermittent irrigated plots but there was no significant variation in LAI between the two treatment combinations. Greater LAI might be due to the contribution of greater number of tillers hill $^{-1}$ in the respective treatment combinations. More et al. (2007) and Gani et al. (2002) also found similar results in their studies.

\subsection{Dry matter hill ${ }^{-1}$}

Dry matter production hill $^{-1}$ at 45 days after transplanting was not influenced significantly by the combined effect of seedlings age and water management (Table 1). The highest dry matter hill $^{-1}$ (211 g) was recorded from 15-d-old seedlings transplanted in intermittent irrigated plots and 30-d-old seedlings transplanted in continuous flooded plots provided the lowest dry matter hill ${ }^{-1}(180 \mathrm{~g})$ whereas the other treatment combinations produced moderate amount of dry matter hill $^{-1}$. At anthesis, 15-d-old seedlings transplanted in intermittent irrigated plots provided the highest dry matter hill $^{-1}(242 \mathrm{~g})$ which was followed by that (228 g) recorded from the seedlings of same age transplanted in continuous flooded plots. Thirty-d-old seedlings transplanted in continuous flooded plots provided significantly the lowest dry matter hill ${ }^{-1}$ $(210 \mathrm{~g})$ which was followed by that $(215 \mathrm{~g})$ recorded from the seedlings of same age transplanted in intermittent irrigated plots. Greater dry matter production hill ${ }^{-1}$ might be due to the contribution of greater number of tillers hill $^{-1}$ and leaf area index in the respective treatment combinations. Planting younger 
seedlings of 15 days age led to significant increase in dry matter production as compared to use of older seedlings of 20 and 28 days age and the extent of increase was 9.62 and $18.80 \%$, respectively (More et al. 2007). Pandey and Yaduwanshi (2007) found significant increase in dry matter accumulation in water saving production of rice. Because submerging rice field brings a series of physical, chemical and microbial changes in the soil, which profoundly affects growth of rice plant as well as availability and absorption of nutrients.

\subsection{Plant height at harvest}

Height at harvest was found to be influenced significantly by the combined effect of seedlings age and water management (Table 2). The tallest $(98.3 \mathrm{~cm})$ plant was recorded from 15-d-old seedlings transplanted in intermittent irrigated plots which was followed by that $(95.0 \mathrm{~cm})$ recorded from intermittent irrigated plots where 30-d-old seedlings were transplanted. Continuous flooded plots transplanted by either 15 or 30 -d-old seedlings provided the shortest plants $(90.4 \mathrm{~cm})$ at harvest. Higher plant height with younger seedlings might be due to vigorous stem elongation of young seedlings (Kim et al. 1999). Thakur (1994) found higher plant height of rice with younger seedlings compared to older seedlings but Murthy et al. (1993) reported that plant height did not vary with the use of different aged seedlings for transplantation.

Table 1. Effect of seedling age and water management on tiller production, leaf area index and dry matter hill ${ }^{-1}$ of BRRI dhan28 at different days after transplanting (DAT)

\begin{tabular}{|c|c|c|c|c|c|c|c|}
\hline \multirow[t]{3}{*}{$\begin{array}{l}\text { Seedlings } \\
\text { age }\end{array}$} & \multirow[t]{3}{*}{ Water management } & \multicolumn{2}{|c|}{ Tillers hill ${ }^{-1}$} & \multicolumn{2}{|c|}{ Leaf area index } & \multicolumn{2}{|c|}{$\begin{array}{c}\text { Dry matter } \\
\left(\mathrm{g} \mathrm{hill}^{-1}\right)\end{array}$} \\
\hline & & At 45 & At & At 45 & At & At 45 & At \\
\hline & & DAT & anthesis & DAT & anthesis & DAT & anthesis \\
\hline \multirow[t]{2}{*}{15 days } & Continuous flooding & $25.2 \mathrm{~b}$ & $27.0 \mathrm{~b}$ & $2.88 \mathrm{~b}$ & $3.03 \mathrm{~b}$ & 194 & $228 \mathrm{~b}$ \\
\hline & Intermittent irrigation & $31.5 \mathrm{a}$ & $32.2 \mathrm{a}$ & $3.51 \mathrm{a}$ & $3.79 \mathrm{a}$ & 211 & $242 \mathrm{a}$ \\
\hline \multirow[t]{2}{*}{30 days } & Continuous flooding & $18.0 \mathrm{~d}$ & $21.2 \mathrm{c}$ & $2.01 \mathrm{~d}$ & $2.35 \mathrm{c}$ & 180 & $210 \mathrm{~d}$ \\
\hline & Intermittent irrigation & $21.3 \mathrm{c}$ & $22.9 \mathrm{c}$ & $2.27 \mathrm{c}$ & $2.57 \mathrm{c}$ & 195 & $215 \mathrm{c}$ \\
\hline \multicolumn{2}{|c|}{ Level of significance } & $*$ & $*$ & $* *$ & $*$ & NS & $*$ \\
\hline \multicolumn{2}{|c|}{$\mathrm{CV}(\%)$} & 5.48 & 5.11 & 3.20 & 5.71 & 1.58 & 1.30 \\
\hline
\end{tabular}

In a column, values followed by different letter(s) are significantly different from each other by DMRT at 5\% level, * indicates significant at 5\% level and NS indicates non significant.

Table 2. Effect of seedlings age and water management on number of tiller hill ${ }^{-1}$ of BRRI dhan 28 at harvest

\begin{tabular}{clccc}
\hline $\begin{array}{c}\text { Seedlings } \\
\text { age }\end{array}$ & Water management & $\begin{array}{c}\text { Plant height } \\
(\mathrm{cm})\end{array}$ & Total tillers hill $^{-1}$ & Effective tillers hill $^{-1}$ \\
\hline 15 days & Continuous flooding & $90.4 \mathrm{c}$ & $23.8 \mathrm{ab}$ & $22.1 \mathrm{~b}$ \\
& Intermittent irrigation & $90.4 \mathrm{c}$ & $25.9 \mathrm{a}$ & $24.9 \mathrm{a}$ \\
\multirow{2}{*}{30 days } & Continuous flooding & $98.3 \mathrm{a}$ & $17.0 \mathrm{c}$ & $15.6 \mathrm{~d}$ \\
& Intermittent irrigation & 95.0 & $21.6 \mathrm{~b}$ & $20.4 \mathrm{c}$ \\
\hline Level of significance & $*$ & $*$ & $*$ \\
$\mathrm{CV}(\%)$ & 1.01 & 1.94 & 6.87 \\
\hline
\end{tabular}

In a column, values followed by different letter(s) are significantly different from each other by DMRT at $5 \%$ level and $*$ indicates significant at $5 \%$ level. 
Table 3. Effect of seedlings age and water management on panicle characteristics of BRRI dhan 28 at harvest

\begin{tabular}{|c|c|c|c|c|}
\hline Seedlings age & Water management & $\begin{array}{l}\text { Panicle length } \\
\text { (cm) }\end{array}$ & $\begin{array}{c}\text { Filled grains } \\
\text { panicle }^{-1}\end{array}$ & $\begin{array}{l}\text { Unfilled grains } \\
\text { panicle }^{-1}\end{array}$ \\
\hline \multirow[t]{2}{*}{15 days } & Continuous flooding & 23.37 & $172 \mathrm{~b}$ & $20 a$ \\
\hline & Intermittent irrigation & 23.45 & $188 \mathrm{a}$ & $21 \mathrm{a}$ \\
\hline \multirow[t]{2}{*}{30 days } & Continuous flooding & 21.38 & $170 \mathrm{c}$ & $14 \mathrm{~b}$ \\
\hline & Intermittent irrigation & 23.67 & $179 \mathrm{~b}$ & $10 \mathrm{c}$ \\
\hline \multicolumn{2}{|c|}{ Level of significance } & $\mathrm{NS}$ & $*$ & $*$ \\
\hline \multicolumn{2}{|c|}{$\mathrm{CV}(\%)$} & 5.08 & 1.80 & 11.96 \\
\hline
\end{tabular}

In a column, values followed by different letter(s) are significantly different from each other by DMRT at $5 \%$ level, * indicates significant at $5 \%$ level and NS indicates non significant.

\subsection{Total tiller hill ${ }^{-1}$ at harvest}

Number of tiller hill ${ }^{-1}$ at harvest was found to be significantly influenced by the interaction effect of seedlings age and water management (Table $2)$. The highest number of tiller hill $^{-1}$ was obtained from intermittent irrigated plots where 15-d-old seedlings were transplanted (25.9) which was followed by that (23.8) obtained from continuous flooded plots where the seedlings of the same age were transplanted but there was no significant variation in tiller hill $^{-1}$ between the two treatment combinations. Thirty-d-old seedlings produced the lowest number of tiller hill $^{-1}$ (17.0) when they were transplanted in continuous flooded plots which was followed by that (21.6) obtained from the seedlings of the same age transplanted in intermittent irrigated plots.

\subsection{Effective tillers hill $^{-1}$ at harvest}

At harvest, number of effective tiller hill $^{-1}$ was significantly influenced by the interaction effect of seedlings age at transplanting and water management (Table 2). Fifteen-d-old seedlings transplanted in intermittent irrigated plots produced the highest number of effective tiller hill $^{-1}$ (24.9) which was followed by that (22.1) when the seedlings of same age was transplanted in continuous flooded plots. Thirty-d-old seedlings produced the lowest number of effective tiller hill $^{-1}$ (15.6) when they were transplanted in continuous flooded plots which was followed by that (20.4) obtained from the seedlings of same age transplanted in intermittent irrigated plots. Singh et al. (2004) found greater number of productive tiller with younger seedlings of rice. Pandey and Yaduwanshi (2007) found greater number of productive tiller in alternate wetting and drying water management than continuous flooding. Stoop et al. (2002) confirmed more effective tillers per hill with younger seedlings in water saving rice production system compared to conventional system

\subsection{Panicle length}

Panicle length was not influenced significantly by the combined effect of seedlings age and water management (Table 3). The longest panicle $(23.67 \mathrm{~cm})$ was recorded from 30 -d-old seedlings transplanted in intermittent irrigated plots and 30-d-old seedlings transplanted in continuous flooded plots provided the shortest panicle $(21.38 \mathrm{~cm})$.

\subsection{Filled grains panicle ${ }^{-1}$}

Number of filled grains panicle ${ }^{-1}$ was significantly influenced by the interaction effect of seedlings age and water management (Table 3 ). The highest number of filled grains panicle ${ }^{-1}$ was obtained from intermittent irrigated plots where 15-d-old seedlings were transplanted (188) which was followed by that (179) obtained from intermittent irrigated plots where 30 -d-old 
seedlings were transplanted. Thirty-d-old seedlings produced the lowest number of filled grains panicle (170) when they were transplanted in continuous flooded plots which was followed by that (172) obtained 15-d-old seedlings transplanted in continuous flooded plots.

\subsection{Unfilled grains panicle $e^{-1}$}

Number of unfilled grains panicle ${ }^{-1}$ was significantly influenced by the interaction effect of seedlings age and water management (Table 3). The highest number of unfilled grains panicle ${ }^{-1}$ was obtained from intermittent irrigated plots where 15-d-old seedlings were transplanted (21) which was followed by that (20) obtained from continuous flooded plots where the seedlings of the same age were transplanted but the variation was not significant. Thirty-d-old seedlings produced the lowest number of unfilled grains panicle ${ }^{-1}(10)$ when they were transplanted in intermittent irrigated plots which was followed by that (14) obtained from 30-d-old seedlings transplanted in continuous flooded plots.

\subsection{Thousand grain weight}

Age of seedlings and water management interacted significantly to influence 1000-grain weight (Table 4$)$. The heaviest grains $(22.61 \mathrm{~g})$ were obtained from continuous flooded plots where 15-d-old seedlings were transplanted and the lightest grains $(21.00 \mathrm{~g})$ obtained from continuous flooded plots where 30-d-old seedlings transplanted. Both 15 and 30-d-old seedlings transplanted in intermittent irrigated plots provided moderate grain weight.

\subsection{Grain yield}

Grain yield was significantly influenced by the interaction effect of seedlings age at transplanting and water management (Table 4). The highest grain yield was obtained from intermittent irrigated plots where 15-d-old seedlings were transplanted $\left(8.77 \mathrm{t} \mathrm{ha}^{-1}\right)$ which was followed by those obtained from 15-d-old seedlings transplanted in continuous flooded plots (7.19 $\left.\mathrm{t} \quad \mathrm{ha}^{-1}\right), \quad 30$-d-old seedlings transplanted in intermittent irrigated plots $(7.19 \mathrm{t}$ $\mathrm{ha}^{-1}$ ) and 30-d-old seedlings transplanted in continuous flooded plots $\left(6.90 \mathrm{t} \mathrm{ha}^{-1}\right)$ though the later three treatment combinations did not differ significantly in grain yield among themselves. The results indicate that younger seedlings performed better in grain yield than older seedlings but intermittent irrigation influenced the grain yield more than continuous flooding. The increment of grain yield in case of younger seedlings and intermittent irrigation was mainly due to increase effective tiller hill ${ }^{-1}$ and increased filled grain panicle ${ }^{-1}$ in the respective treatments. Krishna and Biradarpatil (2009) found significantly higher rice yield ha ${ }^{-1}$ with 12 -d-old seedlings. The per cent increase in the seed yield $\mathrm{ha}^{-1}$ by 12 -d-old seedlings was 21.56 per cent over 25-d-old seedlings. More et al. (2007) found that the grain yield due to use of 15-d-old seedlings was increased by 10.38 and $16.50 \%$ over use of 20 and 28-d-old seedlings, respectively. Anitha and Chellappan (2011) found statistically similar grain yield of rice with intermittent irrigation and continuous flooding in Kerela, India. Shi et al. (2002) conducted an experiment with flooded and intermittent irrigation. It turned out that the intermittent irrigation treatments received 48 and $68 \mathrm{~mm}$ of irrigation water (i.e., 27 and $37 \%$, respectively) less than the flooded treatments, whereas grain yields increased by 4 to $6 \%$. Ginigaddara and Ranamukhaarachchi (2011) confirmed that the yield increase with younger seedlings in water saving rice production system is mainly attributed to more effective tillers per hill, filled grains per plant, panicle length compared to conventional system. It is also associated with greater uptake of nitrogen and manganese by younger seedlings than older seedlings (Mishra and Salokhe, 2008).

\subsection{Straw yield}

Age of seedlings and water management did not interact significantly to influence straw yield (Table 4). The highest straw yield $\left(9.95 \mathrm{t} \mathrm{ha}^{-1}\right)$ was obtained from intermittent irrigated plots where 15-d-old seedlings were transplanted and the lowest straw yield $\left(9.31 \mathrm{t} \mathrm{ha}^{-1}\right)$ was obtained 
from intermittent irrigated plots where 30-d-old seedlings were transplanted. Fifteen and 30-d-old seedlings transplanted in continuous flooded plots provided moderate straw yield.

\subsection{Harvest index}

Age of seedlings and water management interacted significantly to influence harvest of BRRI dhan28 (Table 4). In both water management treatments (continuous flooding and intermittent irrigation) 15-d-old seedlings provided the higher harvest index than that provided by 30 -d-old seedlings but intermittent irrigation influenced the harvest index more than continuous flooding. More et al. (2007) reported that proportion of grain yield to straw yield was more when 15-d-old seedlings were used compared to normally used seedlings of 20 and 28-d-old suggesting efficient translocation of photosynthates from source to sink in former case. Similar observations were reported by Wang et al. (2002).

\subsection{Crop duration}

Duration of BRRI dhan28 (Seed to seed) varied significantly due to different seedling ages at transplanting and water management (Fig. 1). Fifteen-d-old seedlings took shorter time to mature than 30-d-old seedlings in both the water management treatments (continuous flooding and intermittent irrigation). Between the two water management treatments, the crop matured 2 days earlier in intermittent irrigated plots than continuous flooded plots for both aged seedlings. Fig. 1 shows that 15-d-old seedlings took 108 days in intermittent irrigated plots and 110 days in continuous flooded plots whereas 30-d-old seedlings took 118 days in intermittent irrigated plots and 120 days in continuous flooded plots to be matured. Krishna and Biradarpatil (2009) and Reddy and Reddy (1992) also found that younger seedlings matured earlier than the older one in their studies. This might be due to aged seedlings required more days to panicle initiation due to the slow establishment of the seedlings in the main field unlike the younger seedlings and delayed formation of tillers and longer time to recover from transplanting shock resulting in poor yield.

\section{Conclusions}

From the overall results it may be concluded that transplanting of younger seedlings produced more productive tillers hill ${ }^{-1}$ and filled grains panicle $^{-1}$ to increase grain yield. Intermittent irrigation was suitable for exploring the physiological potentials of rice seedlings on effective tillers for increasing grain yield.

Table 4. Effect of seedlings age and water management on grain and straw yield of BRRI dhan28

\begin{tabular}{clcccc}
\hline $\begin{array}{c}\text { Seedling } \\
\text { age }\end{array}$ & Water management & $\begin{array}{c}\text { 1000-grain } \\
\text { weight }(\mathrm{g})\end{array}$ & $\begin{array}{c}\text { Grain yield } \\
\left(\mathrm{t} \mathrm{ha}^{-1}\right)\end{array}$ & $\begin{array}{c}\text { Straw yield } \\
\left(\mathrm{t} \mathrm{ha}^{-1}\right)\end{array}$ & $\begin{array}{c}\text { Harvest } \\
\text { Index }(\%)\end{array}$ \\
\hline 15 days & Continuous flooding & $22.61 \mathrm{a}$ & $7.19 \mathrm{~b}$ & 9.46 & $0.43 \mathrm{~b}$ \\
& Intermittent irrigation & $21.47 \mathrm{~b}$ & $8.77 \mathrm{a}$ & 9.95 & $0.47 \mathrm{a}$ \\
30 days & Continuous flooding & $21.00 \mathrm{~b}$ & $6.90 \mathrm{~b}$ & 9.37 & $0.42 \mathrm{~b}$ \\
& Intermittent irrigation & $21.17 \mathrm{~b}$ & $7.15 \mathrm{~b}$ & 9.31 & $0.43 \mathrm{~b}$ \\
\hline Level of significance & $* *$ & $*$ & $\mathrm{NS}$ & $*$ \\
$\mathrm{CV}(\%)$ & 2.74 & 7.34 & 3.80 & 6.29 \\
\hline
\end{tabular}

In a column, values followed by different letter(s) are significantly different from each other by DMRT at $5 \%$ level, * indicates significant at $5 \%$ level and NS indicates non significant. 


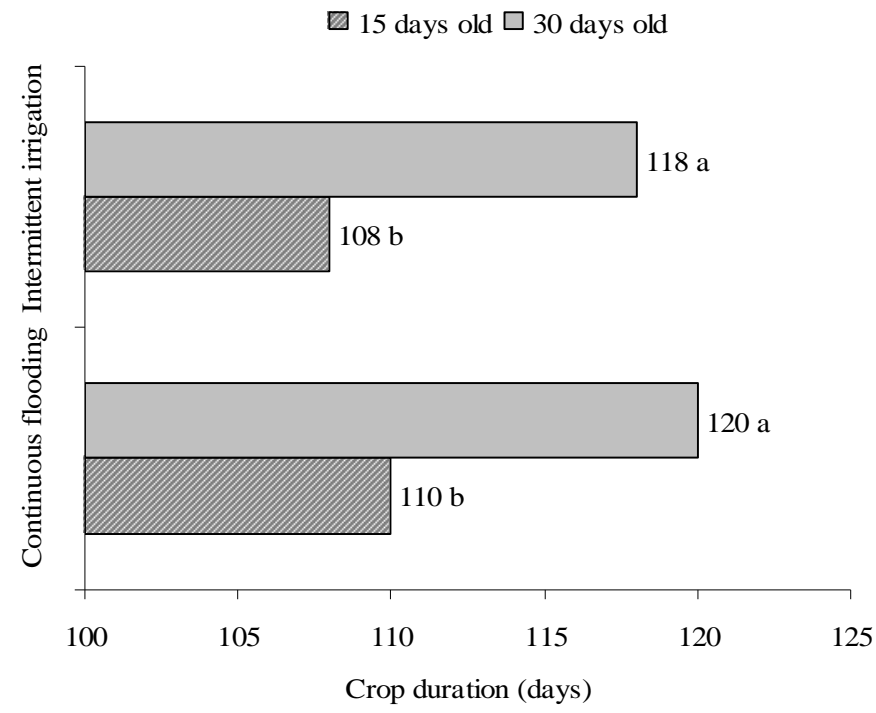

Fig. 1. Effect of seedling age and water management on crop duration of BRRIdhan 28

\section{References}

Anitha S. and Chellappan, M. 2011. Comparison of the system of rice intensification (SRI), recommended practices, and farmers' methods of rice (Oryza sativa L.) production in the humid tropics of Kerala, Indian Journal of Tropical Agriculture, 49 (1-2): 64-71.

BARC (Bangladesh Agricultural Research Council). 2005. Fertilizer Recommendation Guide. BARC, Soils Pub. No. 45, Bangladesh Agricultural Research Council, Farmgate, Dhaka.

Bassi G., Rang, A. and Joshi, D. P. 1994. Effect of seedlings age on flowering of cytoplasmic male sterile and restorer lines of rice. International Rice Research Notes (Philippines), 19(1): 4.

BBS (Bangladesh Bureau of Statistics). 2010. Statistical Year Book of Bangladesh, In: http://www.bbs.gov.bd, People's Republic of Bangladesh, Dhaka, 122 p.
Bouman B. A. M. 2001. Water efficient management strategies in rice production. International Rice Research Newsletter, 26(2):17-22.

Gani A., Rahman, A., Rustam D, and Hengsdijk, H. 2002. Synopsis of water management experiments in Indonesia. In: Water-wise rice production, (eds.). B. A. M., Bouman, Hengsdijk, H., Hardy, B., P. S. Bindraban and Toung T. P. Plant Research International, IRRI, 29-38 pp.

Ghildyal B. P. 1978. Effect of methods of planting and puddling on soil properties and rice growth. Soil and Rice. IRRI, Philippines, 317-336 pp.

Ginigaddara S. G. A. and Ranamukhaarachchi, S. L. 2011. Study of age of seedlings at transplanting on growth dynamics and yield of rice under alternating flooding and suspension of irrigation of water management. Recent Research Science and Technology, 3(3): 76-88. 
Gomez, K. A. and Gomez, A. A. 1984. Statistical Procedure for Agricultural Research. International Rice Research Institute \& John Wiley and Sons, New York, 139-240 pp.

Kim S. S., Kim, B. K., Choi, M. G., Back, N. H., Choi, W. Y. and Lee, S. Y. 1999. Effect of seedlings age on growth and yield on machine transplanted rice in Southern plain region. Korean Journal of Crop Science, 44(2): 122-128.

Krishna A. and Biradarpatil, N. K. 2009. Influence of seedlings age and spacing on seed yield and quality of short duration rice under system of rice intensification cultivation. Karnataka Journal of Agricultural Science, 22(1): 53-55.

Krishna A., Biradarpatil, N. K. and Channappagoudar, B. B. 2008. Influence of System of Rice Intensification (SRI) Cultivation on Seed Yield and Quality. Karnataka Journal of Agricultural Science, 21(3): 369-372.

Makarim A. K., Balasubramanian, V., Zaini, Z., Syamsiah, I., Wardana, I. P. and Gani, A.. 2002. System of Rice Intensification (SRI): Evaluation of seedlings age and selected components in Indonesia. In : Water Wise Rice Production, IRRI, 129$139 \mathrm{pp}$.

Mishra A. and Salokhe, V. M. 2008. Seedlings characteristics and the early growth of transplanted rice under different water regimes. Explanation Agriculture, 44: 119.

Mobasser H. R., Tari, D. B., Vojdani, M.,. Abadi, R. S. and Eftekhari, A., 2007. Effect of Seedlings Age and Planting Space on Yield and Yield Components of Rice (Neda Variety). Asian Journal of Plant Science, 6(2): 438-440.

More M. R., Pawar, L. G., Chavan, S. A, Chavan, P. G. and Misal, R. M. 2007. Effect of methods of raising seedlings and seedlings age and transplanting on growth and yield of rice. In: System of rice intensification in India- Progress and Prospects, (eds.). B., Gujja, Goud, V. V,
Kumar, R. M., Rao, P. P., Prasad, C. S. and Shib, S., Second National Symposium, $3^{\text {rd }}$ to $5^{\text {th }}$ October 2007, Agartala, Tripura, India. 62-65 pp.

Murthy K. K., Pillai, K. G, Srinivasn, T. E. and Ramprasad, A. S. 1993. Rice varieties and technological improvement for late planting during the main kharif season. Seeds and Farms, 49: 9-13.

Pandey N. and O. P. Yaduwanshi. 2007. Effect of planting techniques and water management practices on water use and productivity of rice in Alfisol. In: System of rice intensification in India- Progress and Prospects, (eds.). B., Gujja, Goud, V. V, Kumar, R. M., Rao, P. P., Prasad, C. S. and Shib, S., Second National Symposium, $3^{\text {rd }}$ to $5^{\text {th }}$ October 2007, Agartala, Tripura, India. 105-108 pp.

Pasuquin E., Lafarge, T. and Tubana, B. 2008. Transplanting young seedlings in irrigated rice fields: Early and high tiller production enhanced grain yield. Field Crops Research, 105(1-2): 141- 155.

Reddy K. S. and Reddy, B. B. 1992. Effect of transplanting time, plant density and seedlings age on growth and yield of rice. Indian Journal of Agronomy, 37: 8- 21.

Shi Q., Zeng, X., Li, M., Tan, X. and Xu, F. 2002. Effects of different water management practices on rice growth. In: Water-wise rice production, (eds.). B. A. M., Bouman, Hengsdijk, H., Hardy, B., Bindraban, P. S., Toung, T. P. and Ladha, J. K. Plant Research International, IRRI, 3-14 pp.

Singh K. K., Yadav, S. K., Tomaro, B. S., Singh, J. N. and. Singh, P. K. 2004. Effect of seedlings age on seed yield and seed quality attributes in rice cv. Pusa Basmati1. Seed Research, 32 (1): 5-8.

Singh V. P., Shankar, U. and Bora, P. 2007. Feasibility Study to support System of Rice Intensification (SRI). Retrieved 15th July, 2009, from http://dorabjitatatrust.org/Publications/pdf s/studyreport.pdf. 
Stoop W. A., Uphoff, N. and Kassam, A. 2002. A review of agricultural research issues raised by the system of rice intensification (SRI) from Madagascar: Opportunities for improving farming system for resource-poor farmers. Agricultural Systems, 71:249-274.

Thakur R. B. 1994. Performance of rice varieties as influenced by age of seedlings under late planted condition. Oryza, 31:199-201.
Wang S. H., Weixing, C., Dong, J., Tongbo, D. and Xan, Z. 2002. Physiological characteristics and high yield techniques with SRI rice. In: Assessments of the System of Rice Intensification (SRI), Proc. of the International Conference, Sanya, April 1-4, 2002, 116-124 pp.

Wang Z. Y., Xu, Y. C., Li, Z., Guo, Y. X., Ding, Y. P. and Wang, Z. Z. 1998. Methane emission from rice fields as affected by water region and organic manure input. Acta Agronomica Sinica, 24 (2): 133-138. 